\title{
Pediatric Pain Management Knowledge Scale for Nursing Students: Assessment of the Psychometric Properties
}

\author{
(1) Bahise Aydın¹, (1) Murat Bektaş2 \\ 1 Üsküdar University Faculty of Health Science, Department of Nursing, İstanbul, Turkey \\ 2Dokuz Eylül University Faculty of Nursing, Department of Pediatric Nursing, İzmir, Turkey
}

\begin{abstract}
Aim: This study was designed to determine the psychometric properties of the scale developed to evaluate the pediatric pain management knowledge (PPMK) and the skills of nursing students.

Materials and Methods: This is a methodological study conducted to develop the PPMK scale for nursing students. A 29-item scale was administered to a total of 343 nursing students who were in their $3^{\text {rd }}$ year taking the pediatric nursing course or in their $4^{\text {th }}$ year carrying out their internship training at a state university. The scale items were selected through item-total score correlation analysis, and the sensitivity and specificity of the scale were evaluated using receiver operating characteristic analysis.

Results: The students' mean age was $21.92 \pm 1.150$ years and $76.2 \%$ were female. As a result of explanatory factor analysis, the scale consisting of six subscales was found to explain $50.30 \%$ of the total variance. The fit indexes of confirmatory factor analysis were calculated to be root mean square error of approximation 0.063 , goodness of fit index 0.85 , comparative fit index 0.93 , incremental fit index 0.93 , relative fit index 0.86 , normed fit index 0.88 , and Tucker-Lewis index 0.92. The Cronbach alpha coefficient of the entire scale was determined to be 0.864 . The correlations of the scale items with the scale total score ranged between 0.285 and 0.625 .

Conclusion: In this study, it was determined that the PPMK scale was a valid and reliable tool for nursing students. It is recommended that after the students' knowledge level is determined using the current measurement tool for PPMK, the nursing curriculum should be revised and enriched, and further studies should be conducted on this topic.
\end{abstract}

Keywords: Nurse, student, pediatrics, pain, knowledge

\section{Introduction}

One of the most common symptoms in childhood, pain is an important problem affecting children's growth, healing, mental health, and life quality. In cases where pain cannot be controlled, children, their families, and the community may suffer physiologically, psychosocially, and economically (1). Successful pain management can provide an increase in children's life quality and satisfaction, early mobilization, a shortening of in hospital stay, a decrease economically in treatment costs, and an acceleration in the healing process (2-4).

It is known that children are more sensitive to pain that stems from illness, surgery, and medical procedures

\section{Address for Correspondence}

Asst. Prof. Bahise Aydın, Üsküdar University Faculty of Health Science, Department of Nursing, İstanbul, Turkey

Phone: +90555 5210896 E-mail: bahise.aydin@uskudar.edu.tr ORCID: orcid.org/0000-0001-9815-2843

Received: 15.11.2019 Accepted: 13.02.2020

${ }^{\circ}$ Copyright 2021 by Ege University Faculty of Medicine, Department of Pediatrics and Ege Children's Foundation

The Journal of Pediatric Research, published by Galenos Publishing House. 
$(5,6)$. However, it is extremely difficult to recognize, diagnose, and evaluate pain in children, which challenges the healthcare staff most. Studies in the literature show that nurses working with the pediatric group experience various difficulties and inadequacies in this regard (7-11). It is emphasized in the World Health Organization's 2012 report that pediatric pain is not sufficiently recognized or even ignored by healthcare professionals (12). Therefore, nurses have an important role in the evaluation and management of children's pain during hospitalization. Nurses' knowledge about pain, their behaviors, and self-efficacy in pain management affect nursing care (6). Nursing education is important in making correct pain assessments and followups. It is vital for student nurses to take an inclusive education about pain before their professional life (13-15). In studies evaluating the knowledge and attitudes of nursing students taking pediatrics courses about pediatric pain, it has been determined that students had poor knowledge about pain assessment, and pharmacological and nonpharmacological pain management $(6,9,14-17)$.

It is possible to improve and develop the existing curriculum and teaching methods used in nursing schools by evaluating the quality of education and monitoring the students' level of pain knowledge. Strengthening the pediatric pain management (PPM) education in this regard can lead to successful practices in professional life $(6,15,18)$. In the literature, there are scales developed or adapted to measure nurses' and student nurses' knowledge and attitudes regarding PPM. It has been found that there are very few measurement tools for the evaluation of pediatric pain management knowledge (PPMK) and competencies of student nurses in particular. One of them is the Pediatric Nurses' Knowledge and Attitude Survey Regarding Pain (PNKAS) developed by Manworren (19), which is the modified form of the Nurses' Knowledge and Attitude Survey Regarding Pain created by McCaffery and Ferrell (1997). PNKAS has been used for nursing students in various studies after it was adapted for pediatric nurses $(9,16)$.

Another measurement tool is "The Knowledge and Attitudes of Pain Management Questionnaire" consisting of scenarios and questions about pediatric pain, which was developed by MacLaren et al. (20) to determine the effectiveness of an education program. When both measurement tools were assessed, it was observed that the scales were not up to date, the main focus to control pain was on the use of cognitive-behavioral strategies, the pharmacological dose questions were not suitable for student nurses who had no clinical experience, and that non-pharmacological pain control methods using current technologies such as virtual reality were not addressed $(19,20)$. Therefore, the necessity of developing a scale for all components of PPM including pain awareness, pain pathophysiology, pain management barriers, diagnosis, evaluation, and control of pain has arisen. This scale was designed under the current literature and guidelines, to fit the growth and development characteristics of children, and to cover all the bases of parents and family $(12,19-23)$.

The tools developed for student nurses can measure the knowledge and skills of PPM and evaluate the effectiveness of the basic PPM education and the quality of pain management in practice. However, there is no valid and reliable measurement tool to evaluate the PPMK of student nurses in our country. In the light of the findings of current studies, it was determined that there was a need to develop a valid and reliable scale to evaluate the knowledge and qualifications of students and cover all types of pain and pediatric care areas in children to eliminate the educational shortcomings of nursing students in PPM.

The aim of this study was to develop a valid and reliable measurement tool to assess the knowledge and qualifications of student nurses in PPM. The research question of this study is as follows:

Is the PPM scale for nursing students a valid and reliable tool in determining the student nurses' pain management knowledge level of children?

\section{Materials and Methods}

\section{Study Design, Sampling, and the Population}

This study used a methodological, descriptive, and cross-sectional design to develop "the PPM scale for nursing students" and carry out its validity and reliability studies.

While the sampling size is determined in validity and reliability studies, three rules, namely the $5 \mathrm{~s}, 10 \mathrm{~s}$, and $100 \mathrm{~s}$ rules, are mentioned in the literature. It is emphasized that the researcher should recruit at least five people per item when carrying out factor analysis (24). In the literature, it has been reported that a sampling size less than 100 is considered as insufficient for developing a scale, 100-200 as medium, 200-300 as good, 300-500 as very good, and 500-1.000 as excellent $(25,26)$. This study was conducted with $3^{\text {rd }}$ year students taking a pediatric nursing course and $4^{\text {th }}$ year students carrying out their internship training in the field of pediatric nursing in the spring semester of the 2017-2018 academic year at the Nursing Faculty of a state university. A total of 344 students who agreed to participate in the study voluntarily and filled in the forms were included in the study. 


\section{Socio-demographic Characteristics}

The mean age of the students participating in the study was 21.92 years $( \pm 1.150$, range $=19-26) .76 .2 \%$ of the participants were female and $76.7 \%$ of them had a medium grade point average (50-79). 59.6\% of the participants had not had education in PPM prior to the study. $96.6 \%$ of those who had received PPM education stated they had received it at school as part of the curriculum. It was identified that the majority of the participants (98.8\%) had graduated from a non-health high school (Table I).

\section{Data Collection Tools}

- Demographic Data Form: This is an 8-item form that includes the students' grade point average, age, gender, marital status, the high school which they graduated from, previous PPM training, and type of training if taken and current level of PPM.

- Pediatric Pain Management Knowledge Scale for Nursing Students: This 5-point Likert type scale aiming to measure the PPMK of student nurses was developed by the researchers in light of the related literature $(8,23,27-37)$. The scale consists of 29 items that address the six dimensions of PPM. The scale consists of six subscales for assessing student nurses' knowledge levels and qualifications for pain awareness, pain physiopathology, barriers to pain management, pain diagnosis, assessment, and control of pain. The subscales, items, and answers are as follows. The first subscale addresses pain awareness and it has six items (M1, M2, M5, M6, M7, M50) such as "Babies can't perceive pain." (Correct response: I strongly disagree). The second subscale deals with pain physiopathology and it has four items (M8, M9, M44, M45) such as "Attention, emotion, and memory affect the transmission of pain." (Correct response: I strongly agree). The third subscale is "barriers to pain management" and it has eleven items (M10, M11, M12, M13, M14, M15, M16, M17, M19, M21, M22) such as "The child who maintains his/her activity has no pain." (Correct response: I strongly disagree). The fourth subscale addresses pain diagnosis and it has two items (M24, M25) such as "If the child or his/her mother/caregiver says they have pain, then they have pain." (Correct response: I strongly agree). The fifth subscale is about pain assessment and it has two items

Table I. Demographic data of the nursing students $(n=344)$

\begin{tabular}{|c|c|c|c|c|}
\hline Demographic data & $\mathbf{n}$ & $\%$ & $M$ & SD \\
\hline Grade point average & & & 2.23 & 0.423 \\
\hline $\begin{array}{l}50-79 \\
80-100\end{array}$ & $\begin{array}{l}264 \\
80\end{array}$ & $\begin{array}{l}76.7 \\
23.3\end{array}$ & & \\
\hline Age & & & 21.92 & 1.150 \\
\hline $\begin{array}{l}19-22 \\
23 \text { and over }\end{array}$ & $\begin{array}{l}254 \\
90\end{array}$ & $\begin{array}{l}73.9 \\
26.1\end{array}$ & & \\
\hline Gender & & & - & 0.427 \\
\hline $\begin{array}{l}\text { Female } \\
\text { Male }\end{array}$ & $\begin{array}{l}262 \\
82\end{array}$ & $\begin{array}{l}76.2 \\
23.8\end{array}$ & & \\
\hline Marital status & & & - & 0.54 \\
\hline $\begin{array}{l}\text { Married } \\
\text { Single }\end{array}$ & $\begin{array}{l}1 \\
343\end{array}$ & $\begin{array}{l}0.3 \\
99.7\end{array}$ & & \\
\hline High school & & & - & 0.107 \\
\hline $\begin{array}{l}\text { Health vocational high school } \\
\text { Other }\end{array}$ & $\begin{array}{l}4 \\
340\end{array}$ & $\begin{array}{l}1.2 \\
98.8\end{array}$ & & \\
\hline Previous pain education & & & - & 0.497 \\
\hline $\begin{array}{l}\text { Yes } \\
\text { No }\end{array}$ & $\begin{array}{l}139 \\
205\end{array}$ & $\begin{array}{l}40.4 \\
59.6\end{array}$ & & \\
\hline Type of the eduation & & & - & 1.486 \\
\hline $\begin{array}{l}\text { Course } \\
\text { Seminar } \\
\text { Lesson } \\
\text { Congress }\end{array}$ & $\begin{array}{l}0 \\
3 \\
141 \\
2\end{array}$ & $\begin{array}{l}0.0 \\
2.1 \\
96.6 \\
1.3\end{array}$ & & \\
\hline
\end{tabular}


(M28, M29) such as "For patients who cannot communicate verbally, physiological and/or behavioral pain assessment scales could be used." (Correct response: I strongly agree). The sixth subscale is pain control and it has four items (M30, M33, M46, M47) such as "The treatment of pain is a patient right." (Correct response: I strongly agree). The scale items were rated using a 5-point Likert scale ranging from 1 to 5 (1: Strongly disagree; 2: Disagree; 3: Undecided; 4: Agree; 5: Strongly agree). The lowest score that can be obtained from the scale is 29 , and the highest score is 145 . An increase in scores indicates that the students have more information about PPM.

\section{Ethics Approval}

To conduct this research, approval of the Non-invasive Research Ethics Committee of the University from the Nursing Faculty (IRB: 3970-GOA/2018/11-18) and the nursing faculty, and the written and verbal informed consent of the participants were taken. At the beginning of the study, the aim and procedures were stated to the participants by the researcher, their approval was obtained and they were assured that their knowledge scores would not affect their school grade points. It was stated that the participation of the students in the study was on a voluntary basis and they would be allowed to leave without stating a reason at any stage of the study.

\section{Study Procedure}

All the students included in the study were attending the nursing faculty of a university. They were taking a pediatric nursing course ( $3^{\text {rd }}$ grades) or carrying out their internship training ( $4^{\text {th }}$ grades). After the students were informed in a classroom by the researcher at the end of the semester, they were asked to fill in the required forms. These forms which took approximately 30-40 minutes to complete were collected by the researcher.

\section{Data Collection and Statistical Analysis}

The development stages of the PPM Scale for nursing students were as follows.

- Determination of Draft Scale Items: A literature review was conducted to develop the PPM Scale for Nursing Students. A draft scale item pool consisting of 51 items was formed using relevant databases and the literature.

- Obtaining Expert Opinions: Content validity refers to the extent to which the scale as a whole and each item in the scale serve the purpose. Gözüm and Aksayan (38) stated that the draft prepared for the content validity should be submitted to the opinions of at least three experts and that these experts should come together to present their opinions after making an independent evaluation. After this process, items that fall below the minimum consistency limit should be removed from the scale or rearranged (38). In this study, the draft scale was submitted to expert opinion for content validity. The expert group consisted of 12 faculty members working in pediatric nursing departments of various universities in our country. The scale was sent to these experts via e-mail and they were asked to score each item between 1 and 5 (1: Not appropriate - 5: Fully appropriate) to assess the eligibility of the items. The consistency between the experts participating in the evaluation process was assessed by the content validity index (CVI).

- The Pilot Test of the Draft Scale: It is recommended that after expert opinions are obtained, the scale should be administered to a group of about 10-20 people who have similar characteristics with the subjects of the study but will not be included in the sampling of the study $(24,39)$. The draft scale, which was revised based on expert opinion, was administered to 10 students who met the characteristics of the study sample. At the end of the pilot test, no negative feedback was received regarding the comprehensibility of the items, therefore the researchers decided to use the scale without any modification.

- Reliability Calculations: Pearson correlation analysis was used for the item total score analysis of the scales and subscales, and inappropriate items were removed from the scale by considering the correlation value $0.20(24,39)$. 14 items including M20, M26, M31, M32, M34, M35, M36, M37, M39, M40, M41, M42, M48, and M51 were removed from the scale. Cronbach's alpha coefficient was calculated to determine the internal consistency of the scale and subscales (24,38-40).

- Validity Calculations: Explanatory factor analysis was used to determine the item-factor relationship, and confirmatory factor analysis was employed to see whether the items and subscales explained the original structure of the scale. The items whose factor loads were below 0.30 were removed from the scale (24,38-40). After implementing the explanatory factor analysis, 8 items including M3, M4, M18, M23, M27, M38, M43, and M49 were removed from the scale. Time-invariance was analyzed by t-test and Pearson correlation analysis in dependent groups.

\section{Statistical Analysis}

The following calculations, tests, and analyses were employed in the study: percentage and mean calculations for descriptive statistics; Shapiro-Wilk normality test for 
determining if the data conform to normal distribution; CVI for consistency analysis of the expert opinions; Pearson correlation analysis for item-total score analysis of the scale and subscales; Cronbach's alpha coefficient for determining the internal consistency of the scale and subscales; explanatory factor analysis for determining item-factor relationship; confirmatory factor analysis to determine whether the items and subscales explain the original structure of the scale; t-test for known group comparison; Pearson correlation analysis for determining the relationship between the factors of the scale; and paired sample t-test and Pearson correlation analysis for evaluating test/retest. In the evaluation of the data, the error margin was taken as $p=0.05$.

\section{Results}

\section{Content Validity}

The CVI was determined to be between 0.99 and 1.00 on the item-based content validity index (I-CVI) and 0.99 on the scale-based content validity index (S-CVI).

\section{Explanatory Factor Analysis (EFA)}

As a result of the EFA, the Kaiser-Meyer Olkin (KMO) coefficient was found to be 0.858 , the Bartlett test $X^{2}$ value as 2,715.733, and $p=0.000$. As a result of EFA, it was determined that the scale consisted of six subscales. The scale explained $50.30 \%$ of the total variance. The first subscale (awareness) of the scale was found to explain $23.042 \%$ of the total variance, the second subscale (physiopathology) $8.420 \%$, the third subscale (barriers) $5.643 \%$, the fourth subscale (diagnosis) $4.914 \%$, the fifth subscale (assessment) $4.496 \%$, and the sixth subscale (control) 3.785\%. Table II shows the EFA results of the scale.

The factor loadings of the "awareness" subscale were between 0.402-0.516; those of the "physiopathology" subscale were between $0.363-0.535$, those of the "barriers" subscale were between 0.300-0.540, those of the "diagnosis" subscale were between $0.368-0.471$, those of the "assessment" subscale were between 0.557-0.622, and those of "control" subscale were between 0.552-0.687 (Table II).

\section{Confirmatory Factor Analysis (CFA)}

The calculated chi-square value of the six-factor model was found to be 844.06 , the degree of freedom was 356 , and $\mathrm{p}=0.000$. The $\mathrm{X}^{2} /$ standard deviation section was determined to be 2.370. The fit indexes were calculated to be root mean square error of approximation (RMSEA) $=0.063$, goodness of fit index $(\mathrm{CFI})=0.85$, comparative fit index $(\mathrm{CFI})=0.93$, incremental fit index $(\mathrm{IFI})=0.93$, relative fit index $(\mathrm{RFI})=0.86$, normed fit index $(\mathrm{NFI})=0.88$, and TLI $=0.92$ (Table III).

As a result of the CFA, the factor loadings of the "awareness" subscale was found to be between 0.35-0.52, those of the "physiopathology" subscale were between 0.26-0.51, those of the "barriers" subscale were between $0.27-0.59$, those of the "diagnosis" subscale were between $0.46-0.62$, those of the "assessment" subscale were between 0.46-0.54, and those of the "control" subscale were between 0.58-0.70 (Figure 1).

In Table IV, the mean total score of the upper group, which accounted for $27 \%$ of the group, was $132.98+4.35$, while it was $104.60+8.16$ for the lower group. The difference between the mean scores of the groups was statistically significant $(p=0.000)$.

Hotelling's T squared test was used to reveal whether there was a response bias and the values for the test were found to be $1626.983, F=53.533$ and $p=0.000$. As a result of this test, it was determined that there was no response bias in the scale. The additivity feature of the scale was analyzed using Tukey additivity analysis and it was determined to be $F=3.077$ and $p=0.079$. Therefore, the scale was found to be summable.

Cronbach's alpha coefficient of the entire scale was 0.864 . The alpha values of the subscales were 0.635 for the "awareness" subscale, 0.425 for the "physiopathology" subscale, 0.734 for the "barriers" subscale, 0.445 for the "diagnosis" subscale, 0.394 for the "assessment" subscale, and 0.766 for the "control" subscale. As a result of the split-half analysis, the Cronbach's alpha value of the first half was 0.791 and that of the second half was 0.746 . The Spearman-Brown coefficient was 0.825 . The Guttmansplit-half coefficient was 0.822 . The correlation coefficient between the two halves was found to be 0.703 . There was no floor effect for the entire scale and there was a ceiling effect at the limits in the assessment and control subscales. These values are given in Table $\mathrm{V}$.

The correlations of the scale items with a total score of the scale ranged between 0.285 and 0.625 . The itemsubscale total score correlations were between 0.4500.632 for the "awareness" subscale, 0.557-0.622 for the "physiopathology" subscale, $0.383-0.645$ for the "barriers" subscale, 0.745-0.852 for the "diagnosis" subscale, 0.7080.858 for the "assessment" subscale, and 0.700-0.807 for the "control" subscale (Table VI). 
Table II. The results of explanatory factor analysis $(n=344)$

\begin{tabular}{|c|c|c|c|c|c|c|}
\hline \multirow{2}{*}{ Items } & \multicolumn{6}{|c|}{ Factor loads of the subscales } \\
\hline & Awareness & Physiopathology & Barriers & Diagnosis & Assessment & Control \\
\hline M1 & 0.451 & & & & & \\
\hline M2 & 0.453 & & & & & \\
\hline M5 & 0.402 & & & & & \\
\hline M6 & 0.516 & & & & & \\
\hline M7 & 0.465 & & & & & \\
\hline M50 & 0.499 & & & & & \\
\hline M8 & & 0.363 & & & & \\
\hline M9 & & 0.535 & & & & \\
\hline M44 & & 0.497 & & & & \\
\hline M45 & & 0.371 & & & & \\
\hline M10 & & & 0.364 & & & \\
\hline M11 & & & 0.455 & & & \\
\hline M12 & & & 0.473 & & & \\
\hline M13 & & & 0.359 & & & \\
\hline M14 & & & 0.540 & & & \\
\hline M15 & & & 0.300 & & & \\
\hline M16 & & & 0.357 & & & \\
\hline M17 & & & 0.406 & & & \\
\hline M19 & & & 0.433 & & & \\
\hline M21 & & & 0.300 & & & \\
\hline M22 & & & 0.450 & & & \\
\hline M24 & & & & 0.471 & & \\
\hline M25 & & & & 0.368 & & \\
\hline M28 & & & & & 0.557 & \\
\hline M29 & & & & & 0.622 & \\
\hline M30 & & & & & & 0.663 \\
\hline M33 & & & & & & 0.552 \\
\hline M46 & & & & & & 0.583 \\
\hline M47 & & & & & & 0.687 \\
\hline Explained variance (\%) & 23.042 & 8.420 & 5.643 & 4.914 & 4.496 & 3.785 \\
\hline $\begin{array}{l}\text { Overall } \\
\text { explained variance (\%) }\end{array}$ & 50.30 & & & & & \\
\hline Eigenvalue & 6.682 & 2.442 & 1.637 & 1.425 & 1.304 & 1.098 \\
\hline KMO & 0.858 & & & & & \\
\hline Bartlett $X^{2}(p)$ & $2715.733(0.000)$ & & & & & \\
\hline
\end{tabular}




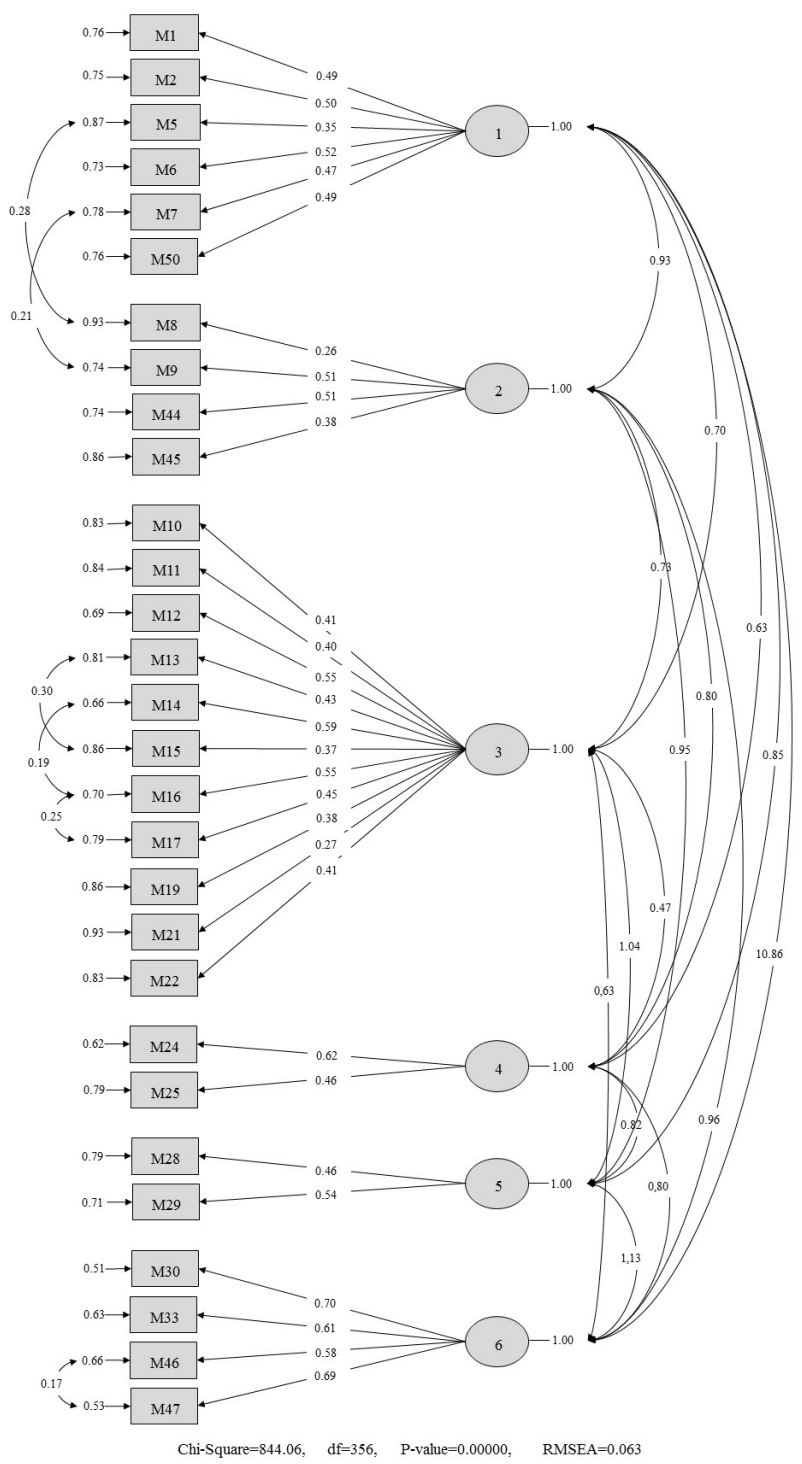

Figure 1. Confirmatory factor analysis RMSEA: Root mean square error of approximation

\section{Discussion}

It was observed that the CVIS were over 0.80 on the I-CVI and S-CVI, there was a high level of fit among the experts, and that the items represented the desired field adequately $(41,42)$. These results were found to support the content validity of the scale.

\section{Construct Validity of the Scale}

It was reported in the literature that to do a factor analysis, the Barlett Sphericity test value should be statistically significant and the KMO value should be at least $0.60(41,42)$. In this study, the value of the Barlett Sphericity test was $\mathrm{p}<0.05$ and the $\mathrm{KMO}$ value was greater than 0.60 $(p=0.000, K M O$ value $=0.858)$. These results indicated that the data of the study were adequate and appropriate for factor analysis (41-44).

In the EFA, the eigenvalue was accepted as 1 or above in determining the factor number (43). It was determined that the scale consisted of six subscales. The six subscales explained $50.30 \%$ of the total variance. The total explained variance in this study was more than $50 \%$ and this revealed that the scale was a valid measurement tool. These results also supported the construct validity of the scale. When determining under which factor the items would fall within, it is emphasized in the literature that the minimum factor load should be 0.30 or above and that those items below this value should be removed (41-44). In this study, it was determined that the factor loadings of the items in the "awareness", "assessment", and "control" subscales were greater than 0.40, those of the "physiopathology" and "diagnosis" subscales were greater than 0.36, and that the factor loadings of the items in the "barriers" subscale were greater than 0.30. In this study, the total explained variance was greater than $50 \%$ and the factor loadings were greater

Table III. Fit indexes of the model

\begin{tabular}{|l|l|l|l|l|l|l|l|l|l|l|} 
& $\mathbf{X}^{2}$ & $\mathbf{S D}^{\mathrm{a}}$ & $\mathbf{X}^{2} / \mathbf{S D}$ & $\mathbf{R M S E A}^{\mathbf{b}}$ & GFI $^{\mathbf{c}}$ & CFI $^{\mathbf{d}}$ & IFI $^{\mathbf{e}}$ & RFI $^{\mathbf{f}}$ & $\mathbf{N F I}^{\mathbf{g}}$ & TLI $^{\mathrm{h}}$ \\
\hline $\begin{array}{l}\text { Six-factor } \\
\text { model }\end{array}$ & 844.06 & 356 & 2.370 & 0.063 & 0.85 & 0.93 & 0.93 & 0.86 & 0.88 & 0.92 \\
\hline
\end{tabular}

SD: Standard deviation, RMSEA: Root mean square error of approximation, GFI: Coodness of fit index, CFI: Comparative fit index, IFI: Incremental fit index, RFI: Relative fit index, NFI: Normed fit index, TLI (NNFI): Trucker-lewis index

Table IV. Comparison of the upper and lower groups, each of which represented $27 \%(n=344)$

\begin{tabular}{|l|l|l|l|l|l|}
\hline Class & $\mathbf{n}$ & $\mathbf{M}$ & SD & t & p \\
\hline $\mathbf{2 7 \%}$ Upper group & 93 & 132.98 & 4.35 & \multirow{2}{*}{29.589} & 0.000 \\
\hline $\mathbf{2 7 \%}$ Lower group & 93 & 104.60 & 8.16 & & \\
\hline SD: Standard deviation
\end{tabular}


Table V. The reliability analysis results of the scale and subscales $(n=344)$

\begin{tabular}{|c|c|c|c|c|c|c|c|c|c|c|}
\hline Subscales & $\begin{array}{l}\text { Cronbach's } \\
\alpha\end{array}$ & $\begin{array}{l}\text { First half } \\
\text { cronbach } \\
\alpha\end{array}$ & $\begin{array}{l}\text { Second } \\
\text { half } \\
\text { cronbach } \\
\alpha\end{array}$ & $\begin{array}{l}\text { Spearman- } \\
\text { brown }\end{array}$ & $\begin{array}{l}\text { Guttman } \\
\text { split-half }\end{array}$ & $\begin{array}{l}\text { Correlation } \\
\text { between } \\
\text { the two } \\
\text { halves }\end{array}$ & $M$ & SD & $\begin{array}{l}\text { Floor } \\
\text { effect } \\
\%\end{array}$ & $\begin{array}{l}\text { Ceiling } \\
\text { effect } \\
\%\end{array}$ \\
\hline Entire scale & 0.864 & 0.791 & 0.746 & 0.825 & 0.822 & 0.703 & 118.90 & 11.84 & 0.0 & 0.6 \\
\hline Awareness & 0.635 & - & - & - & - & - & 26.41 & 2.84 & 0.0 & 10.8 \\
\hline Physiopathology & 0.425 & - & - & - & - & - & 16.04 & 2.20 & 0.3 & 7.0 \\
\hline Obstacles & 0.734 & - & - & - & - & - & 42.50 & 5.69 & 0.0 & 0.9 \\
\hline Diagnosis & 0.445 & - & - & - & - & - & 8.02 & 1.47 & 0.0 & 20.0 \\
\hline Assessment & 0.394 & - & - & - & - & - & 8.31 & 1.33 & 0.6 & 22.4 \\
\hline Control & 0.766 & - & - & - & - & - & 17.59 & 2.11 & 0.0 & 25.3 \\
\hline
\end{tabular}

Table VI. Total score correlations for the item-scale and the item-subscales $(n=344)$

\begin{tabular}{|c|c|c|c|}
\hline Subscales & Items & Item-scale total score correlations $(r)^{*}$ & Item-subscale score correlations $(\mathbf{r})^{*}$ \\
\hline \multirow{6}{*}{ Awareness } & M1 & 0.443 & 0.632 \\
\hline & M2 & 0.427 & 0.613 \\
\hline & M5 & 0.452 & 0.631 \\
\hline & M6 & 0.489 & 0.588 \\
\hline & M7 & 0.441 & 0.626 \\
\hline & M50 & 0.436 & 0.450 \\
\hline \multirow{4}{*}{ Physiopathology } & M8 & 0.441 & 0.622 \\
\hline & M9 & 0.503 & 0.557 \\
\hline & M44 & 0.454 & 0.602 \\
\hline & M45 & 0.358 & 0.611 \\
\hline \multirow{11}{*}{ Barriers } & M10 & 0.441 & 0.531 \\
\hline & M11 & 0.473 & 0.419 \\
\hline & M12 & 0.523 & 0.621 \\
\hline & M13 & 0.424 & 0.571 \\
\hline & M14 & 0.561 & 0.645 \\
\hline & M15 & 0.381 & 0.565 \\
\hline & M16 & 0.557 & 0.629 \\
\hline & M17 & 0.441 & 0.562 \\
\hline & M19 & 0.430 & 0.403 \\
\hline & M21 & 0.285 & 0.383 \\
\hline & M22 & 0.446 & 0.431 \\
\hline \multirow[b]{2}{*}{ Diagnosis } & M24 & 0.437 & 0.745 \\
\hline & M25 & 0.379 & 0.852 \\
\hline \multirow[b]{2}{*}{ Assessment } & M28 & 0.584 & 0.858 \\
\hline & M29 & 0.563 & 0.708 \\
\hline \multirow{4}{*}{ Control } & M30 & 0.591 & 0.700 \\
\hline & M33 & 0.479 & 0.769 \\
\hline & M46 & 0.525 & 0.787 \\
\hline & M47 & 0.625 & 0.807 \\
\hline *Significant at $p<0.0$ & & & \\
\hline
\end{tabular}


than 0.30, which indicated that the scale had the necessary capacity to measure the pain knowledge correctly and that the scale had strong construct validity.

As a result of CFA, it was found that the factor loadings of all six subscales other than two items were greater than 0.30 , whereas the factor loadings of items 8 and 15 were $0.26,0.27$, respectively (Figure 1). The explanatory factor loadings of these two items were greater than 0.30 and they had a good correlation with the item total and subscale total score, which suggested that the scale was entirely correlated. As a result, they were not removed from the scale as it indicated that the scale was adequate in measuring the pain concept. When the fit indexes of the scale were analyzed, it was determined that the fit indexes were greater than $0.85(\mathrm{GFI}=0.85, \mathrm{IFI}=0.93, \mathrm{NFI}=0.88$, $\mathrm{CFI}=0.93)$, RMSEA value was 0.063 and $\mathrm{X}^{2} / \mathrm{df}$ was 2.370 (Table III). According to the literature, fit indexes greater than 0.85 , RMSEA values less than 0.08 , and $X^{2} / d f$ less than 5 confirm the factor structure of a scale. The DFA results showed that the scale confirmed the six-factor structure, the subscales were correlated with the scale, and that the items in each subscale defined their own factor sufficiently (41-43).

The results of the explanatory and confirmatory factor analysis in this study supported the construct validity of the scale and proved that the scale was a valid tool.

\section{Reliability of the Scale}

\section{Internal Consistency Analysis of the Scale and Subscales}

A Cronbach's alpha coefficient value of lower than 0.60 indicates low reliability for a scale, a value between 0.60 and 0.80 indicates the scale is quite reliable, and a value between 0.80 and 1.00 shows the scale is highly reliable $(45,46)$. In this study, the Cronbach's alpha coefficient was found to be 0.864 for the entire scale. It was determined that the Cronbach's alpha coefficient of the "awareness", "barriers", and "control" subscales were greater than 0.60 and that the coefficient was less than 0.60 for "physiopathology", "diagnosis" and "assessment" subscales. The reliability levels were found to be quite high for the entire scale and three of the subscales, whereas it was found to be lower for the other three subscales. However, when the entire scale was considered, the most important evidence that indicated items of the scale made up a whole was the Cronbach's alpha value which was calculated for the entire scale. The Cronbach's alpha value for the entire scale was 0.86 and it was a highly reliable value. Therefore, it was concluded that these subscales could be used on the scale, too. Moreover, both the explanatory and confirmatory factor analysis constituted a good correlation matrix for the entire subscales and between the subscales, which indicated that the scale and its subscales could be used. When the literature was reviewed, the Cronbach's alpha value and Kuder-Richardson-20 value were found to be 0.64 and 0.69 , respectively, for the measurement tool developed in the study of Salanterä and Lauri (17), in which they studied the knowledge and views of nursing students about pediatric pain. The Cronbach's alpha value found by Manworren (19) for the scale adapted for pediatric nurses was 0.72 . The Cronbach's alpha value of the Norwegian version of the same scale was 0.71 (47). The Cronbach's alpha value of another scale, which was developed to measure the pain management beliefs of nurses, was 0.83 from the pretest and 0.85 from the posttest (11). The internal consistency values obtained in this study and the values of other scales were similar. The results of this study indicated that the scale could be used reliably for nursing students. In this study, the Cronbach's alpha values found as a result of the split-half method and Spearman-Brown and Guttmansplit-half coefficients were found to be greater than 0.70 , indicating a strong and significant relationship between the two halves. These results were important evidence supporting the reliability of the scale. These results revealed that each item was highly correlated with the entire scale and the subscales, the items represented the areas to be measured adequately, the scale measured the PPMK level of the nursing students satisfactorily, and that the scale and the subscales had high reliability.

\section{Item-total Score Analysis of the Scale and Subscales}

It is recommended that the item-total score and the item-subscale total score correlations should be greater than 0.20 and as close to 1 as possible, and positive (24). It was determined in this study that the total scores of the items and the total scores of the subscales and their correlations were found to be mainly over 0.25 (Table $\mathrm{VI})$. With these results, it was observed that each item was highly correlated with both the entire scale and the subscales, they represented the areas to be measured adequately, the scale measured the PPMK level of the nursing students satisfactorily, and that the item reliability of the scale and the subscales were high.

It is predicted that the scale developed to measure PPMK of nursing students will contribute to the literature in evaluating the qualification and efficacy of pediatric pain education in nursing students. Additionally, it is 
thought that increasing the awareness of nursing students in PPM in their future lives by improving their skills will contribute to helping students gain sufficient knowledge of physiopathology, better pain diagnosis, assessment, control, and the effective management of barriers that can be encountered in pain management in practice.

\section{Study Limitations}

There are some limitations in the study despite having many strengths. The first limitation is the use of a convenience sampling method. This may affect the generalizability of the study. However, this study can provide insights about the importance of revision to the nursing curricula and improving it to improve knowledge of PPM. Further research is required to confirm the current research findings and to investigate all practice areas of nursing students for PPM.

\section{Conclusion}

As a result of this study, it was found that the scale was valid and reliable in evaluating nursing students' qualifications in PPM. With this study, the literature has gained an objective measurement tool for the assessment of the PPM knowledge level of nursing students. Using this scale, students' knowledge levels can be determined. The scale can be used for validity and reliability studies of both nurses and other health workers. It may lead to the spread of the scale to other nursing areas, the planning of further studies on these areas, and the assessment of the effectiveness of the current education.

\section{Ethics}

Ethics Committee Approval: To conduct this research, approval of the Non-invasive Research Ethics Committee of the University from the Nursing Faculty (IRB: 3970GOA/2018/11-18).

Informed Consent: The written and verbal informed consent of the participants were taken.

Peer-review: Externally and internally peer-reviewed.

\section{Authorship Contributions}

Concept: M.B., B.A., Design: M.B., B.A., Data Collection or Processing: M.B., B.A., Analysis or Interpretation: M.B., Writing: B.A.

Conflict of Interest: No conflict of interest was declared by the authors.

Financial Disclosure: The authors declared that this study received no financial support.

\section{References}

1. Ung A, Salamonson Y, Hu W, Gallego G. Assessing knowledge, perceptions and attitudes to pain management among medical and nursing students:A review of the literature. Br J Pain 2016; 10:8-21.

2. Büyükgönenç L, Kılıçarslan Törüner $E$. Pain in Childhood and Nursing Management. In: Conk Z, Başbakkal Z, Bal Yılmaz H, Bolışık B (eds). Pediyatri Hemşireliği (Pediatrik Nursing). Ankara: Akademisyen Kitabevi;2017; 91-106.

3. Kortesluoma RL, Nikkonen M, Serlo W. "You just have to make the pain go away" - Children's experiences of pain management. Pain Management Nursing 2008; 9:143-9.

4. Twycross A, Dowden S). Status of pediatric nurses' knowledge about pain. Pediatric Pain Letter 2009;11:17-21.

5. Ameringer S, Fisher D, Sreedhar S, Ketchum JM, Yanni L. Pediatric pain management education in medical students: Impact of a web-based module. I Palliat Med 2012; 15:978-83.

6. Chiang LC, Chen HI, Huang L. Student nurses' knowledge, attitudes, and self-efficacy of children's pain management: Evaluation of an education program in Taiwan. Pain Symptom Manage 2006; 32:82-9.

7. Ekim A, Ocakcı AF. Knowledge and attitudes regarding pain management of pediatric nurses in Turkey. Pain Manag Nurs 2013; 14:e262-97.

8. Göl İ, Onarici M. Nurses' knowledge and practices about pain and pain control in children. Journal of Hacettepe University Faculty of Nursing 2015; 2:20-9.

9. Ortiz MI, Ponce-Monter HA, Rangel-Flores E, et al. Nurses' and nursing students' knowledge and attitudes regarding pediatric pain. Nurs Res Pract 2015; 2015:210860. doi: 10.1155/2015/210860.

10. Rieman MT, Gordon M. Pain management competency evidenced by a survey of pediatric nurses' knowledge and attitudes. Pediatr Nurs 2007; 33:307-12.

11. Vincent $\mathrm{CVH}$, Wilkie DJ, Wang E. Pediatric nurses' beliefs and pain management practices: An intervention pilot. West I Nurs Res 2011; 33:825-45.

12. WHO guidelines on the pharmacological treatment of persisting pain in children with medical illnesses. France: WHO Library Cataloguing in Publication Data, 2012.

13. Eti Aslan F, Badır A. Reality about pain control: The knowledge and beliefs of nurses on the nature, assessment and management of pain. Agri 2005; 17:44-51.

14. Dirimeşe E, Özdemir FK, Şahin ZA. Nursing students' knowledge of related to pain management, cultural awareness and competence. Gümüşhane University Journal of Health Sciences 2016; 5:1-6.

15. Laprise J. Identification of student nurses' knowledge and attitudes regarding pediatric pain management. University Scholar Projects; Paper 28, 2016. Last Accessed Date: 25.06.2018 Available from: http://digitalcommons.uconn.edu/usp_ projects $/ 28$

16. Omari OA. Knowledge and attitudes of Jordanian nursing students toward children's pain assessment and management: A cross-sectional study. I Nurs Educ Pract 2016; 6:51-8.

17. Salanterä S, Lauri S. Nursing students' knowledge of and views about children in pain. Nurse Educ Today 2000; 20:537-47. 
18. Gadallah MAEA, Hassan AM, Shargawy SAEH. Undergraduate nursing students' knowledge and attitude regarding pain management of children in Upper Egypt. I Nurs Educ Pract 2017; 7:100-7.

19. Manworren RCB. Development and testing of the pediatric nurses' knowledge and attitudes survey regarding pain. Pediatr Nurs 2001; 27:151-8.

20. MacLaren JE, Cohen LL, Larkin KT, Shelton EN. Training nursing students in evidence-based techniques for cognitive-behavioral pediatric pain management. J Nurs Educ 2008; 47:351-8.

21. American Academy of Pediatrics, Committee on Psychosocial Aspects of Child and Family Health; Task Force on Pain in Infants, Children, and Adolescents. The assessment and management of acute pain in infants, children, and adolescents. Pediatrics 2001; 108:793-7.

22. Hauer ), Houtrow AJ. Pain assessment and treatment in children with significant impairment of the central nervous system -American Academy of Pediatrics clinical report. Pediatrics 2017;139:e20171002. doi:10.1542/peds.2017-1002.

23. Hockenberry MJ, Wilson D. Study guide to accompany Wong's nursing care of infants and children. 8th ed. USA: Mosby Elsevier; 2007; 143-5.

24. Şencan H. Reliability and validity in social and behavioral measurement. 1st ed. Ankara:Seçkin Yayınevi;2005:867.

25. Comrey AL, Lee HB. A first course in factor analysis. 2nd ed. New York:Psychology Press;1992; 216-7.

26. Misirli ZA, Akbulut Y. Development of a scale to explore technology literacy skills of Turkish 8th graders. Contemp Educ Technol 2013; 4:249-62.

27. Al-Motairy MO. Nursing student's knowledge and application of pain assessment at King Saud University. Master Thesis. King Saud University Nursing College, Kingdom of Saudi Arabia (1431H-2010G). 2010.

28. Manworren R. Pediatric nurses' knowledge and attitudes survey regarding pain, 1999. Last Accessed Date: 24.06.2018 Available from: http://prc.coh.org/pdf/ped_KA survey.pdf.

29. Plaisance L, Logan C. Nursing students' knowledge and attitudes regarding pain. Pain Manag Nurs 2006; 7:167-75.

30. Rosner C, Kiehne AM. Study guide for Ashwill and Droske nursing care of children: Principles and practice. USA:W.B Saunders Company;1997; 93-9.

31. Senol YY. Determination of goals and objectives in medical education programs. In: Sayek I (eds.) Medical trainer handbook. Ankara: Güneş Tıp Kitabevleri;2016; 85-8.

32. Tufekci FG, Ozlu ZK, Arslan S, Gumus K. Knowledge and attitudes regarding pain management of oncology and non- oncology nurses in Turkey. Global Advanced Research / Nurs Midwifery 2013; 2:1-8.

33. Twycross A, Williams A. Establishing the validity and reliability of a pediatric pain knowledge and attitudes questionnaire. Pain Manag Nurs 2013; 14:e47-53.

34. Walco GA, Goldschneider KR. Pain in children: A practical quide for primary care. USA:Humana Press;2008:21-7.

35. Woldehaimanot TE, Saketa YJ, Zeleke AM, Hailay Abrha Gesesew HA, Woldeyohanes TR. Pain knowledge and attitude: A survey among nurses in 23 health institutions in Western Ethiopia. Gaziantep Med I 2014; 20:254-60

36. Yorulmaz G. Evaluation of the students' knowledge about pain in nursing school. Master Thesis. İstanbul Bilim Üniversitesi, istanbul 2012

37. Zanolin ME, Visentin M, Trentin L, Saiani L, Brugnolli A, Grassi M. A questionnaire to evaluate the knowledge and attitudes of health care providers on pain. I Pain Symptom Manage 2007; 33:727-36.

38. Gözüm S, Aksayan S. Guideline for intercultural scale adaptation II: Psychometric characteristics and cross-cultural comparison. Hemşirelikte Araştırma Geliştirme Dergisi 2003; 4:9-20.

39. Şimşek ÖF. Introduction to structural equation modeling, LISREL fundamental principles and practices. İstanbul:Ekinoks yayınları;2010:212.

40. Akgül A. Statistical analysis techniques in medical research. 2nd eds. Ankara;Emek Ofset: 2003:602.

41. DeVellis RF. Scale development: Theory and applications. 3rd ed. New York:Sage Publications; 2012; 115-47.

42. Johnson B, Christensen L. Educational research: Quantitative, qualitative, and mixed approaches. 3rd ed. California:Sage Publication; 2007; 277-309.

43. Hayran M, Hayran M. Basic istatistics for health surveys. 2nd ed. Ankara:Omega Research Publication; 2018; 311-24.

44. Terwee $C B$, Bot $S D$, de Boer $M R$, et al. Quality criteria were proposed for measurement properties of health status questionnaires. J Clin Epidemiol 2007; 60:34-42.

45. Nunnally JC, Bernstein IH. Psychometric theory. 3rd ed. New York;McGraw-Hill:2010.

46. Rattray J, Jones MC. Essential elements of questionnaire design and development. J Clin Nurs 2007; 16:234-43.

47. Hovde KR, Granheim TH, Christophersen KA, Dihle A. The Norwegian version of the pediatric nurses' knowledge and attitudes survey regarding pain: Reliability and validity. Pediatr Nurs 2012; 38:264-9. 